\section{Metabolic Clearance and Plasma Disappearance Rates of Human Pancreatic Tumor Growth Hormone Releasing Factor in Man}

\author{
Lawrence A. Frohman, Jennifer L. Thominet, \\ Cheryle B. Webb, Mary Lee Vance, Howard Uderman, \\ Jean Rivier, Wylie Vale, and Michael O. Thomer \\ Divisions of Endocrinology and Metabolism, Departments of \\ Medicine, University of Cincinnati, Cincinnati, Ohio 45267; \\ University of Virginia, Charlottesville, Virginia 22908; and \\ Vanderbilt University, Nashville, Tennessee 37232; and Peptide \\ Biology Laboratory, Salk Institute, La Jolla, California 92138
}

ologic characteristics of plasma IR-GRF, $30 \mathrm{~min}$ after injection, were similar to those of synthetic hpGRF(140). The results have been discussed in relation to the MCR of other hypothalamic hormones and have been used to extrapolate secretion rates of GRF in patients with ectopic GRF production.

\section{Introduction}

Growth hormone secretion is regulated by both stimulatory and inhibitory factors of hypothalamic origin. The inhibitory factor is represented by somatostatin, a tetradecapeptide, which appears to be similar in all mammalian species from which it has been isolated to date (1). Growth hormone releasing factor (GRF) ${ }^{1}$ has recently been isolated and sequenced from ectopic sites of production in two pancreatic islet tumors (human pancreatic GRF [hpGRF]) (2-4). In one tumor only a single GRF with a 40-amino acid sequence was isolated (3-5), whereas the other tumor contained the identical GRF as the major component along with 44- and 37-amino acid peptides (2). The structure of human hypothalamic GRF remains to be determined, though preliminary evidence indicates that it is similar in physicochemical and immunologic characteristics to ectopic GRF (6, 7); and two immunologically related peptides which coeluted with hpGRF(1-40) and hpGRF(1-44) have now been isolated and show identical tryptic digest patterns and amino acid composition (8).

The rapid decrease in serum GH levels after removal of a GRF-secreting tumor suggests a rapid metabolic clearance of GRF (9). However, administration of hpGRF(1-40) to normal human subjects resulted in a rise in serum growth hormone levels (10) that persisted, after high doses, for up to $3 \mathrm{~h}$, and

1. Abbreviations used in this paper: $\mathrm{ACN}$, acetonitrile; hpGRF, human pancreatic GRF; IR, immunoreactive; KIU, kallikrein inactivator units; GRF, growth hormone releasing factor; MCR, metabolic clearance rate. 
frequently exhibited a biphasic pattern (11). Since the clearance of growth hormone from circulation is fairly rapid (12), the persistence of growth hormone secretion for this prolonged duration indicated a continuous effect of $h p G R F(1-40)$ and implied a slower metabolic clearance of the peptide than has been reported for other hypophysiotropic hormones such as thyrotropinreleasing hormone, gonadotropin-releasing hormone, and somatostatin (13-15). The present studies were therefore performed to determine the metabolic clearance rate (MCR) and plasma disappearance time of hpGRF (1-40) in normal human subjects with both single-injection and constant-infusion techniques.

\section{Methods}

\section{Clinical studies}

SUBJECTS STUDIED. Experiments were performed in 18 healthy adult male subjects whose ages ranged from 22 to $30 \mathrm{yr}$ and who were within $15 \%$ of ideal body weight. All subjects gave informed, written consent. Experiments were conducted under identical protocols in the General Clinical Research Centers at the University of Cincinnati and University of Virginia Hospitals to which subjects were admitted the evening before or the morning of study. The subjects consumed no food for $10 \mathrm{~h}$ before or during the study. Indwelling butterfly needles were placed in forearm veins and kept patent with heparinized saline for infusion/injection and blood sampling. Blood pressure and pulse were monitored throughout the study at frequent intervals. Subjects were studied in random order in each of the protocols.

HORMONE PREPARATION. All experiments were performed with hpGRF $(1-40)$, which was synthesized $(3,4)$ and prepared $(10)$ as previously described.

PROTOCOLS. Single injection protocol. After obtaining a basal sample, subjects were given a rapid intravenous injection of hpGRF $(1-40)$ at a dose of $1,3.3$, or $10 \mu \mathrm{g} / \mathrm{kg}$. Blood samples were collected at $5,10,15$, $30,60,120$, and $180 \mathrm{~min}$, placed into heparinized tubes containing aprotinin (Trasylol, FBA Pharmaceuticals, New York) sufficient to provide a final concentration of 1,000 kallikrein inactivator units (KIU)/ $\mathrm{ml}$ blood, chilled, centrifuged, and stored at $-70^{\circ} \mathrm{C}$. Samples were shipped to Cincinnati on dry ice for subsequent analysis.

Constant infusion protocol. After a 90-min control period, subjects were infused for four consecutive 90 -min periods with hpGRF(1-40) at rates of $1,3.3,10$, and $33 \mathrm{ng} / \mathrm{kg}$ per min, respectively, in a volume of $0.3-0.5 \mathrm{ml} / \mathrm{min}$. hpGRF(1-40) was diluted appropriately with saline from an initial concentration of $100 \mu \mathrm{g} / \mathrm{ml}$ containing $1 \%$ human serum albumin. Blood samples were collected in heparinized tubes containing aprotinin, $1,000 \mathrm{KIU} / \mathrm{ml}$ blood, every $15 \mathrm{~min}$ during the infusion and at $1,3,5,10,15,20,30,45,60$, and $90 \mathrm{~min}$ after termination of the infusion, and handled as described above.

\section{Radioimmunoassay of $G R F$}

hpGRF (1-40) was radioiodinated by the chloramine T method (16), in which $0.2 \mathrm{mCi}$ of $\mathrm{Na}^{125} \mathrm{I}, 1 \mu \mathrm{g}$ peptide, and $10 \mu \mathrm{g}$ chloramine $\mathrm{T}$ were reacted for $15 \mathrm{~s}$. Sodium metabisulphite, $60 \mu \mathrm{g}$, and $0.2 \%$ bovine serum albumin, $0.2 \%$, were then added to terminate the reaction. ${ }^{125} \mathrm{I}$-hpGRF(140) was purified by high performance liquid chromatography by application on $\mathrm{a} \mathrm{C}_{18}$ (Waters Associates, Millipore Corp., Milford, MA) column and elution with a $30-40 \%$ acetonitrile (ACN) gradient in 0.01 $M$ trifluoroacetic acid (TFA). Anti-GRF serum was prepared in a rabbit by immunization with hpGRF(1-20)-human alpha globulin complex and used at a final dilution of $1: 12,500$. The antiserum exhibited no significant cross-reactivity $\left(<5 \times 10^{-6}\right)$ to other hypothalamic, pituitary, gastrointestinal, or pancreatic hormones. The initial incubation, consisting of ${ }^{125}$ I-hpGRF(1-40), anti-GRF serum, and standard or sample was performed in $0.05 \mathrm{M}$ phospho-saline buffer, $\mathrm{pH} 6.0$, containing $1 \%$ bovine serum albumin and $0.04 \mathrm{M}$ EDTA in a total volume of $250 \mu \mathrm{l}$ for $48 \mathrm{~h}$ at $4^{\circ} \mathrm{C}$, followed by immediate precipitation with sheep antirabbit IgG and polyethylene glycol (PEG 6000). Precipitate radioactivity was analyzed by a weighted log-logit method on an Apple computer (Apple Computer, Inc., Cupertino, CA). The intra- and inter-assay coefficients of variation were 6.5 and $7.8 \%$, respectively, at a level of 200 $\mathrm{pg} /$ tube. The sensitivity of the assay varied between 10 and $20 \mathrm{pg} /$ tube.

\section{Plasma extraction}

$1 \mathrm{ml}$ of plasma was applied to a $\mathrm{C}_{18}$ Sep-pak (Waters Associates), previously activated by successive applications of $0.01 \mathrm{M} \mathrm{TFA}, 80 \% \mathrm{ACN}$ / TFA, and $0.01 \mathrm{M}$ TFA. The column was then washed with $2 \mathrm{ml}$ TFA and eluted with $80 \%$ ACN/TFA. The eluate was rapidly frozen and lyophilized. The samples were reconstituted in radioimmunoassay or bioassay buffer before measurement.

\section{Validation of plasma assay}

DEGRADATIVE EFFECTS OF PLASMA ON RADIOLABELED hpGRF(1-40). The effects of plasma on the immunoreactivity of ${ }^{125}$ I-hpGRF $(1-$ 40) were determined by preincubating plasma in the absence or presence of aprotinin, 1,000 KIU/ml, with labeled hpGRF(1-40) for varying times at $4^{\circ}$ and $37^{\circ} \mathrm{C}$. After this period, anti-GRF serum was added; and the mixture was incubated and then co-precipitated, as described above.

SEPHADEX CHROMATOGRAPHY. Nonextracted or Sep-pak extracted plasma samples were gel filtered on a $1-\times 80-\mathrm{cm}$ Sephadex G50 (Pharmacia Fine Chemicals, Piscataway, NJ) column, equilibrated, and eluted with $0.05 \mathrm{M}$ phospho-saline buffer containing $1 \%$ bovine serum albumin and $0.05 \mathrm{M}$ disodium EDTA, $\mathrm{pH}$ 6.0, at a flow rate of $0.25 \mathrm{ml} / \mathrm{min}$ at $4^{\circ} \mathrm{C}$. The column was calibrated with blue dextran (void volume), hpGRF(1-40), and sodium chloride (elution volume).

\section{Bioassay of $G R F$}

GRF activity of plasma extracts was measured in a dispersed rat pituitary cell monolayer culture system as previously described $(17,18)$, which was modified by using serum-free media supplemented with bovine insulin, $10 \mu \mathrm{g} / \mathrm{ml}$, and corticosterone, $10^{-8} \mathrm{M}$ (Sigma Chemical Co., St. Louis, MO), during the $4 \mathrm{~d}$ before testing. Growth hormone release was measured during a 4-h incubation period in quadruplicate cultures. At the end of the incubation, the media was collected and frozen for subsequent radioimmunoassay of rat growth hormone as previously described (19).

\section{Data analyses}

SINGLE INJECTION STUDIES. Biexponential analysis of the plasma disappearance of immunoreactive (IR)-GRF was carried out with the SAAM 27 curve-fitting computer program (20). The data were fitted to the biexponential equation $\mathrm{C}(t)=-A \mathrm{e}^{\alpha t}+B \mathrm{e}^{-\beta t}$, where $t=$ time, $\mathrm{C}(t)$ $=$ the plasma concentration of IR-GRF at each time point, and $A$ and $\alpha$ are the parameters for the alpha (distribution) and $B$ and $\beta$ the parameters for the beta (elimination) phases, respectively. The MCR was calculated as the dose administered divided by the area under the curve (AUC), which was calculated as AUC $=A / \alpha+B / \beta$. The volume of distribution was calculated as the dose administered $/(A+B)$. The halftime for each phase was calculated as $\mathrm{t}_{1 / 2}=\ln 2 / \alpha$ or $/ \beta$. 
CONSTANT INFUSION STUDIES. The metabolic clearance rate was calculated during each of the four infusion periods by the following formula: MCR (milliliters per minute) = rate of infused hpGRF(1-40) (nanogram per minute)/plasma IR-GRF (nanogram per milliliter). The mean of two or three separate plasma IR-GRF determinations, obtained after equilibrium had been reached, was used to calculate the MCR for each subject at each time period.

POSTINFUSION DISAPPEARANCE RATE DETERMINATION.Analysis of the plasma disappearance of IR-GRF after cessation of a constant infusion was performed with a linear regression program. The data were fitted to the equation $\ln C(t)=\ln C(o)-\alpha t$, where $t=$ time and $C(t)$ $=$ plasma concentration of IR-hpGRF at each time point. (This equation is a linear tranformation of a monoexponential disappearance curve.) The slope of the regression line, $\alpha$, was used to calculate the disappearance half-time as $t_{1 / 2}=\ln 2 / \alpha$. The anti-ln of the intercept, i.e., $\mathrm{C}(o)$, represents the calculated steady state concentration of plasma IR-GRF before cessation of the infusion.

GROUP COMPARISONS. Results are expressed as mean \pm SEM. The $t$ test or an analysis of variance was used to determine the statistical significance of differences between group means.

\section{Results}

GRF immunoreactivity in normal plasma. Measurement of IRGRF levels in unextracted plasma resulted in levels of 2.1 \pm 0.09 $\mathrm{ng} / \mathrm{ml}$ (mean \pm SEM) in 27 normal subjects. However, endogenous IR-GRF was eluted from Sephadex G-50 in the void volume and thus did not coincide with the elution position of synthetic hpGRF(1-40) when the latter was applied either in buffer or together with plasma. Addition of synthetic hpGRF(140 ) to plasma in the range of $0.1-10 \mathrm{ng} / \mathrm{ml}$ resulted in virtually complete recovery.

When plasma from normal subjects was applied to a Seppak, endogenous IR-GRF was not retained. Immunoassay of the lyophilized and reconstituted $80 \%$ ACN/TFA effluent resulted in undetectable levels $(<124 \mathrm{pg} / \mathrm{ml})$ in nine subjects. Addition of synthetic hpGRF(1-40) $(5 \mathrm{ng} / \mathrm{ml})$ to plasma immediately before its application to Sep-pak columns resulted in an $80.1 \pm 2.2 \%$ recovery $(n=38)$. There was no significant difference in recovery when Sep-paks were used in a recycled manner for up to 11 applications.

These findings were interpreted to indicate that endogenous GRF immunoreactivity in unextracted plasma was attributable to a yet undefined material(s) distinct from GRF. Consequently, all subsequent measurements of IR-GRF levels were performed on extracted plasma. Values were not corrected for recovery.

The addition of aprotinin to plasma prevented the degradation $(<5 \%)$ of ${ }^{125} \mathrm{I}-\mathrm{hpGRF}(1-40)$ for at least $48 \mathrm{~h}$ at $4^{\circ} \mathrm{C}$ and $2 \mathrm{~h}$ at $37^{\circ} \mathrm{C}$. In the absence of aprotinin, significant $(>10 \%)$ degradation was noted after 6 and $1 \mathrm{~h}$, respectively.

Single injection studies. Plasma IR-GRF levels were undetectable in all of the subjects before GRF injection. Levels of IR-GRF at each of the time periods are shown in Fig. 1. The combined disappearance curve is shown in Fig. 2, where the data has been transformed as a function of the injected dose. The disappearance of IR-GRF from plasma could be fitted to

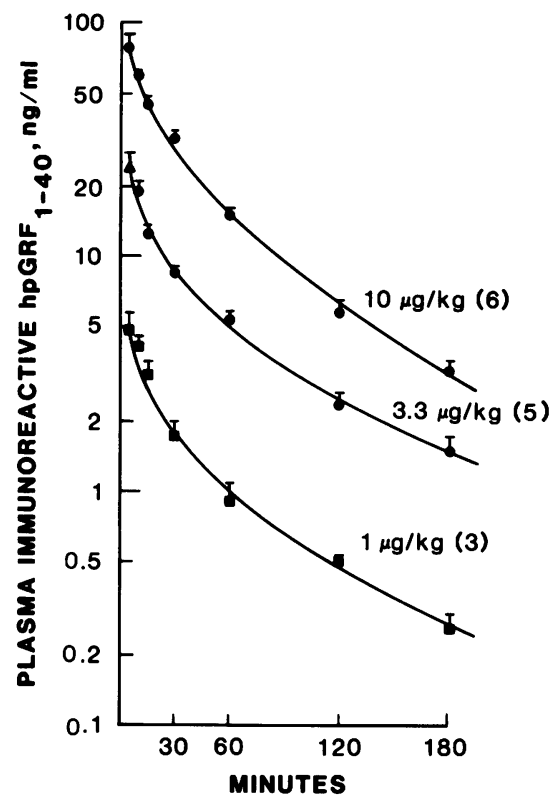

Figure 1. Plasma IR-GRF levels at various times after the injection of $1,3.3$, or $10 \mu \mathrm{g} / \mathrm{kg}$ hpGRF(1-40). Shown are the mean \pm SE.

a biexponential curve and displayed paralleled behavior over the range of doses administered. The relevant parameters obtained from the analysis of the curves are shown in Table I. The disappearance half-times from the alpha (distribution) and beta (elimination) phases were 7.6 \pm 1.2 and $51.8 \pm 5.4 \mathrm{~min}$, respectively. The MCR was $194 \pm 17.5$ liters $/ \mathrm{m}^{2}$ per $\mathrm{d}$ and the

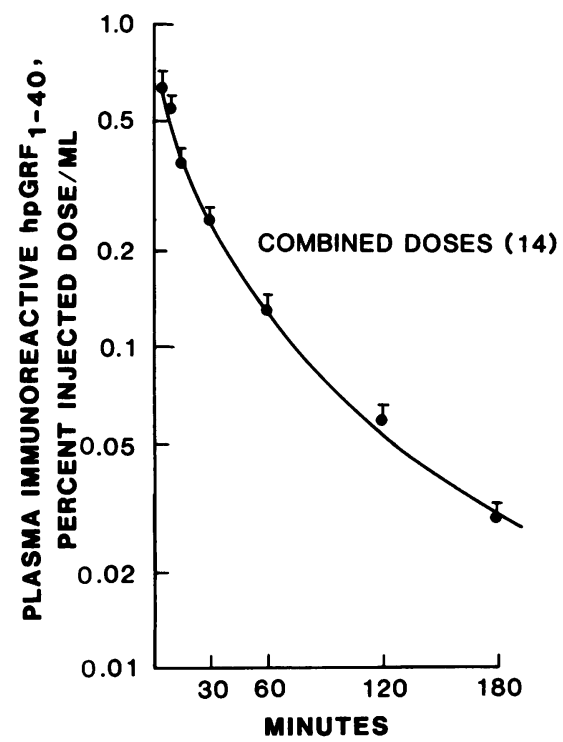

Figure 2. Composite plasma IR-GRF levels after the injection of hpGRF $(1-40)$. Shown are the mean \pm SE of the results, which have been corrected with respect to the quantity of $h p G R F(1-40)$ injected. 
Table I. MCR of $h p G R F(1-40)$ after Single Injection

\begin{tabular}{|c|c|c|c|c|c|c|c|}
\hline \multirow[t]{2}{*}{ Subject } & \multirow{2}{*}{$\begin{array}{l}\text { Weight } \\
\mathrm{kg}\end{array}$} & \multirow{2}{*}{$\begin{array}{l}\text { Surface area } \\
m^{2}\end{array}$} & \multirow{2}{*}{$\begin{array}{l}\text { GRF dose } \\
\mu g / k g\end{array}$} & \multicolumn{2}{|c|}{ Disappearance $\left(t_{1 / 2}\right)$} & \multirow{2}{*}{$\begin{array}{l}\text { MCR } \\
\text { liters } / m^{2} / d\end{array}$} & \multirow{2}{*}{$\begin{array}{l}\text { Volume of distribution } \\
\text { liters }\end{array}$} \\
\hline & & & & $\min$ & $\min$ & & \\
\hline & & & & $\alpha$ & $\beta$ & & \\
\hline 1 & 75.9 & 2.0 & 1 & 4.0 & 35.3 & 197 & 5.0 \\
\hline 2 & 80.0 & 2.0 & 1 & 6.7 & 43.9 & 261 & 12.0 \\
\hline 3 & 46.6 & 1.4 & 1 & 7.6 & 29.2 & 367 & 8.6 \\
\hline 3 & 46.6 & 1.4 & 3.3 & 8.1 & 45.6 & 172 & 5.9 \\
\hline 4 & 98.2 & 2.1 & 3.3 & 3.3 & 85.0 & 157 & 3.3 \\
\hline 6 & 89.0 & 2.0 & 3.3 & 2.8 & 61.3 & 113 & 1.6 \\
\hline 8 & 73.5 & 1.9 & 3.3 & 4.6 & 37.4 & 199 & 6.7 \\
\hline 10 & 84.0 & 2.8 & 3.3 & 2.2 & 35.0 & 174 & 6.4 \\
\hline 1 & 75.9 & 2.0 & 10 & 17.9 & 98.0 & 168 & 9.9 \\
\hline 5 & 82.7 & 2.2 & 10 & 10.3 & 43.0 & 153 & 8.2 \\
\hline 6 & 89.0 & 2.0 & 10 & 8.1 & 60.3 & 152 & 7.9 \\
\hline 7 & 85.0 & 2.0 & 10 & 14.5 & 59.7 & 200 & 10.2 \\
\hline 9 & 89.9 & 2.1 & 10 & 5.5 & 32.5 & 265 & 8.8 \\
\hline 10 & 84.0 & 2.8 & 10 & 11.4 & 59.7 & 138 & 9.6 \\
\hline Mean & 78.6 & 2.05 & & 7.6 & 51.8 & 194 & 6.6 \\
\hline SEM & 4.0 & 0.11 & & 1.2 & 5.4 & 17.5 & 0.8 \\
\hline
\end{tabular}

calculated initial volume of distribution was $6.6 \pm 0.8$ liters. There was no significant difference between the MCR, or the $t_{1 / 2} \beta$ between the doses studied, which suggested nonsaturation of the elimination mechanism.

Constant infusion studies. Plasma IR-GRF levels during the constant infusion of $h p G R F(1-40)$ at rates of $1,3.3,10$, and $33 \mathrm{ng} / \mathrm{kg}$ per min are shown in Fig. 3. Plasma IR-GRF levels appeared to stabilize $\sim 60$ min after the start of each infusion and the MCR was calculated from plasma values measured after this time. Table II contains the MCR calculations in these subjects. There was no significant difference between the MCR at the different infusion rates. The overall mean MCR was $202 \pm 16$ liters $/ \mathrm{m}^{2}$ per $\mathrm{d}$.

Plasma IR-GRF levels were measured in eight subjects after discontinuation of the $33 \mathrm{ng} / \mathrm{kg}$ per min infusion. The plasma levels could be fit to a single exponential curve during the 90min postinfusion period and the results are shown in Fig. 4. Analysis of the plasma disappearance curves yielded a half-time of $41.3 \pm 3.0 \mathrm{~min}$ when analyzed as individual curves (Table III) and $47.7 \mathrm{~min}$ when analyzed as a composite curve. The calculated concentration before the cessation of infusion was $8.43 \pm 1.15 \mathrm{ng} / \mathrm{ml}$, a value similar to that observed experimentally $(8.51 \pm 1.92 \mathrm{ng} / \mathrm{ml})$.

Gel filtration of plasma after $h p G R F(1-40)$ injection. The Sephadex G-50 elution pattern of plasma obtained $30 \mathrm{~min}$ after the injection of hpGRF(1-40), $10 \mu \mathrm{g} / \mathrm{kg}$, is shown in Fig. 5. All of the GRF immunoreactivity eluted in a single peak with a dissociation constant $\left(K_{d}\right)$ of 0.48 which coincided with the elution position of hpGRF(1-40) standard.
Bioassay/radioimmunoassay comparison. Plasma samples from three subjects, obtained $30 \mathrm{~min}$ after the injection of hpGRF(1-40), $3.3 \mu \mathrm{g} / \mathrm{kg}$, were Sep-pak-extracted and bioassayed for growth hormone-releasing activity. Basal plasma samples that were similarly processed did not exhibit any growth hormone-releasing activity and did not alter the slope of the elevation

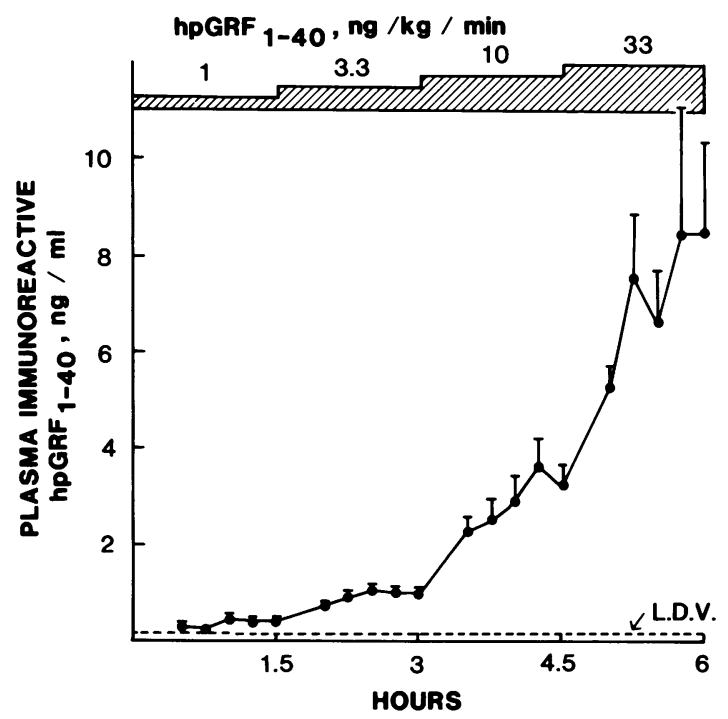

Figure 3. Plasma IR-GRF levels during a stepwise infusion of hpGRF $(1-40)$ over a $6-h$ period. Shown are the mean $\pm S E$ of results in four subjects. L.D.V., least detectable value in radioimmunoassay. 
Table II. MCR of hpGRF(1-40) during Constant Infusion

\begin{tabular}{|c|c|c|c|c|c|c|}
\hline \multirow[t]{2}{*}{ Subject } & \multirow{2}{*}{$\begin{array}{l}\text { Weight } \\
k g\end{array}$} & \multirow{2}{*}{$\begin{array}{l}\text { Surface area } \\
m^{2}\end{array}$} & \multirow{2}{*}{$\begin{array}{l}\text { GRF dose } \\
\mathrm{ng} / \mathrm{kg} / \mathrm{min}\end{array}$} & \multirow{2}{*}{$\begin{array}{l}\text { Plasma IR-GRF } \\
n g / m l\end{array}$} & \multicolumn{2}{|c|}{ MCR } \\
\hline & & & & & $\mathrm{ml} / \mathrm{kg} / \mathrm{min}$ & liters $/ \mathrm{m}^{2} / d$ \\
\hline \multirow[t]{4}{*}{11} & 83.6 & 2.1 & 1 & 0.26 & 3.85 & 221 \\
\hline & & & 3.3 & 1.20 & 2.75 & 158 \\
\hline & & & 10 & 4.35 & 2.30 & 132 \\
\hline & & & 33 & 6.15 & 5.37 & 308 \\
\hline Mean \pm SEM & & & & & $3.57 \pm .68$ & $205 \pm 39$ \\
\hline \multirow[t]{4}{*}{12} & 71.4 & 1.87 & 1 & 0.43 & 2.33 & 128 \\
\hline & & & 3.3 & 0.86 & 3.86 & 212 \\
\hline & & & 10 & 2.20 & 4.55 & 250 \\
\hline & & & 33 & 4.99 & 6.61 & 363 \\
\hline Mean \pm SEM & & & & & $4.34 \pm .89$ & $238 \pm 49$ \\
\hline \multirow[t]{4}{*}{13} & 83.4 & 1.97 & 1 & 0.38 & 2.66 & 162 \\
\hline & & & 3.3 & 1.04 & 3.18 & 194 \\
\hline & & & 10 & 3.43 & 2.92 & 178 \\
\hline & & & 33 & 13.45 & 2.45 & 149 \\
\hline Mean \pm SEM & & & & & $2.80 \pm .16$ & $171 \pm 10$ \\
\hline \multirow[t]{4}{*}{14} & 78.0 & 1.91 & 1 & 0.33 & 3.08 & 181 \\
\hline & & & 3.3 & 1.01 & 3.27 & 192 \\
\hline & & & 10 & 3.00 & 3.33 & 196 \\
\hline & & & 33 & 9.12 & 3.62 & 213 \\
\hline Mean \pm SEM & & & & & $3.32 \pm .11$ & $196 \pm 7$ \\
\hline \multicolumn{5}{|c|}{ Overall mean $\pm \mathrm{SEM}$ at mean level at equilibrium } & $3.38 \pm .34$ & $202 \pm 16$ \\
\hline
\end{tabular}

of the dose response curve of hpGRF(1-40). Bioassay of the 30-min postinjection plasma revealed bioactive GRF levels of $20.3,11.1$, and $6.5 \mathrm{ng} / \mathrm{ml}$, which compared with corresponding IR-GRF levels of $14.1,7.1$, and $4.8 \mathrm{ng} / \mathrm{ml}$.

\section{Discussion}

Several methods are available for the measurement of metabolic clearance and disappearance rates of peptide hormones normally present in plasma. They differ most notably in the choice of single injection vs. constant infusion protocols, the use of natural/ synthetic vs. isotopically labeled peptide, and the technique used to detect the exogenously administered hormone. The constant infusion protocol $(21,22)$ and the single injection technique $(23,24)$ provide generally similar estimates of the MCR and can be used to confirm the results with each other, as was done in the present study. The choice of labeled vs. nonlabeled hormone is more complicated since each introduce a certain problem. Radiolabeled hormones, in order to possess sufficient specific activity, are prepared with ${ }^{125} \mathrm{I}$ or ${ }^{131} \mathrm{I}$, which not only exposes the experimental subject to ionizing radiation but results in a chemically modified hormone, possibly with altered bioactivity, which may be eliminated from circulation by routes dissimilar to that of the natural compound. Furthermore, techniques to measure the radioactive hormone in plasma after administration must demonstrate that the measured radioactivity is still in the same chemical form as originally prepared. Differences in the plasma disappearance rate of ${ }^{125} \mathrm{I}$-labeled insulin and nonlabeled insulin have been demonstrated (25) and relate to this problem. The use of nonlabeled hormones, in contrast, requires a validated method to assay the hormone in plasma and a means of distinguishing endogenous from exogenous hormone.

In preliminary experiments we demonstrated that unextracted plasma contains material(s) that displaced ${ }^{125} \mathrm{I}-\mathrm{hpGRF}(1-$ 40) from antibody, resulting in apparent plasma IR-GRF levels of $\sim 2 \mathrm{ng} / \mathrm{ml}$. Evidence that this plasma immunoreactivity was not hpGRF $(1-40)$ was provided by its void volume elution on Sephadex G-50 and its lack of retention on the Sep-pak. Reversephase cartridges have previously been used successfully by us and others for extraction of small peptides from tissue (26) and 


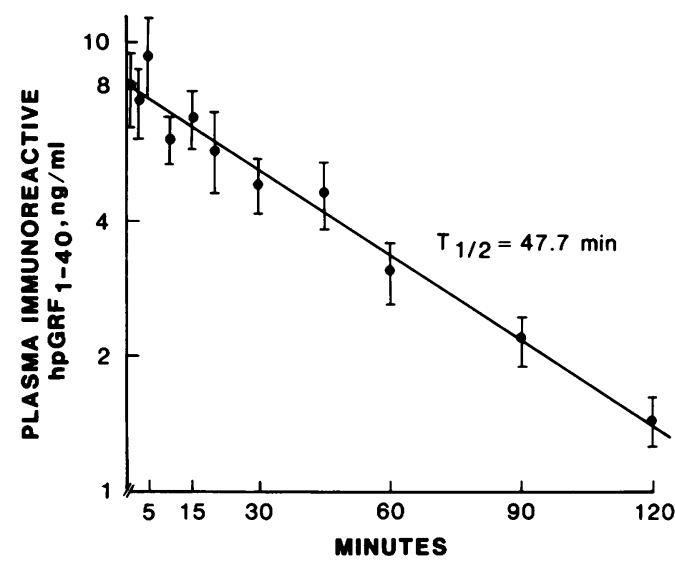

Figure 4. Plasma IR-GRF levels after discontinuation of the constant infusion of hpGRF(1-40) as shown in Fig. 3. Shown are the mean $\pm \mathrm{SE}$ of results in eight subjects.

plasma (27). Normal plasma, after elution from the cartridge, contained no detectable IR-GRF and therefore no problem was encountered in distinguishing endogenous from exogenous GRF. The use of radioimmunoassay as a technique for measuring the infused or injected hpGRF(1-40) was required because of the low levels present. Consequently, there was the possibility that metabolic degradation of injected hpGRF $(1-40)$ would lead to the formation of immunoreactive fragments that differed from hpGRF $(1-40)$ in size or biologic activity. This was assessed by Sephadex gel filtration and by bioassay of postinjection samples. Under the conditions tested, no evidence was found for the presence of GRF fragments with altered size or reduced bioactivity.

Table III. Plasma Disappearance Rate of $h p G R F(1-40)$ after Cessation of Constant Infusion

\begin{tabular}{ll}
\hline Subject & Disappearance time $\left(\mathrm{t}_{1 / 2}\right)$ \\
\hline & $\min$ \\
11 & 51.9 \\
12 & 50.5 \\
13 & 41.0 \\
14 & 41.2 \\
15 & 34.7 \\
16 & 25.8 \\
17 & 45.5 \\
18 & 40.1 \\
Mean \pm SEM & $41.3 \pm 3.0$
\end{tabular}

The disappearance time was determined by linear regression analysis of In (plasma IR-GRF) vs. time. $t_{1 / 2}=0.693 /(-$ slope). A constant infusion of $\mathrm{hpGRF}(1-40), 33 \mathrm{ng} / \mathrm{kg} / \mathrm{min}$ for $90 \mathrm{~min}$, was used to provide a steady state condition.

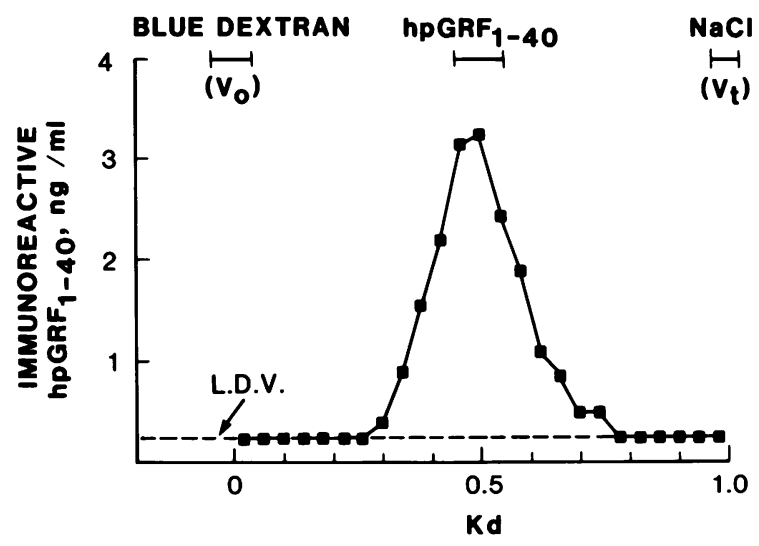

Figure 5. Sephadex G-50 (0.05 $\mathrm{M} \mathrm{PO}_{4}$-saline buffer, $\left.\mathrm{pH}, 6.0\right)$ elution pattern of plasma IR-GRF obtained $30 \mathrm{~min}$ after injection of hpGRF(1-40), $10 \mu \mathrm{g} / \mathrm{kg}$. Plasma (1 ml) was Sep-pak-extracted and gel filtered as described in Methods. Void volume $\left(\mathrm{V}_{0}\right)$ and elution volume $\left(\mathrm{V}_{t}\right)$ were determined using blue dextran and $\mathrm{NaCl}$, respectively. The position of $h p G R F(1-40)$ standard was determined on a separate gel filtration. L.D.V., least detectable value in radioimmunoassay.

The MCR of hpGRF(1-40), as determined by the constant infusion and single injection techniques, varied by $<5 \%$ and were statistically indistinguishable from one another. The metabolic clearance was independent of dose in each of the studies, indicating that mechanisms for removal of GRF from plasma had not reached saturation.

The disappearance curves after the single injection of hpGRF (1-40) differed from those after discontinuation of the constant infusion with the former exhibiting a biexponential curve and the latter a monoexponential curve. This can readily be explained by the fact that the biexponential curve represents the composite of an equilibration phase ( $\alpha$-phase), representing the filling of the extra vascular compartment, and an elimination phase ( $\beta$-phase), representing the irreversible removal of IRGRF from plasma. The monoexponential curve observed after termination of the constant infusion indicates the presence of a predominant $\beta$-phase, since the extravascular compartment was filled and equilibrated during the period of constant infusion. The similarity of the half-times calculated from the two techniques strongly supports this interpretation.

The clearance of $h p G R F(1-40)$ from human plasma is considerably slower than that of several other hypothalamic hormones (thyrotropin-releasing hormone, gonadotropin-releasing hormone, somatostatin) whose $t_{1 / 2}$ ranges from 1 to $10 \mathrm{~min}$ (13-15) but is similar to that of corticotropin-releasing factor (28). This is in part related to the size of $\operatorname{hpGRF}(1-40)$ which is similar to the 41 -amino acid corticotropin-releasing factor but much larger than the other peptides which range from 3to 14-amino acids. However, factors other than size are also important since the plasma disappearance rate of ACTH, a 39amino acid peptide, is considerably faster. In contrast to hpGRF(1-40), ACTH is extremely susceptible to plasma deg- 
radation, which also contributes to its relatively shorter halflife (29).

Knowledge of the MCR of a hormone is important in determining its production rate which, with respect to peptide hormones, represents its secretion rate. This has its greatest significance when the hormone is transported from the site of its secretion to its site(s) of action through the same circulation as is used to study its metabolic clearance. For GRF and the other hypothalamic hormones, however, these criteria are not fulfilled since their physiologic circulation is restricted to the hypothalamic-pituitary portal system, only a few millimeters in length. This distance is sufficiently small and the time required to reach the target cells in the pituitary is correspondingly short, so considerations of metabolic clearance are of little biologic importance.

In contrast, these considerations do not apply when ectopic GRF production (30) is considered. Here, the MCR becomes of great importance since GRF must travel through the peripheral circulation to reach the pituitary. The stability of hpGRF(140) in plasma and its relatively slow MCR result in higher plasma levels and greater biologic effects at the same secretion rate than would otherwise occur.

If plasma hormone levels are measureable, knowledge of the MCR can provide an indication of the secretion rate (secretion rate $=\mathrm{MCR} \times$ plasma level) of the peptide by the tumor. In one patient with ectopic GRF production (9) we have determined the plasma IR-GRF level to be $3.8 \mathrm{ng} / \mathrm{ml}$ (Frohman, L. A., J. L. Thominet, and M. O. Thorner, manuscript in preparation), which results in a calculated secretion rate of $21 \mu \mathrm{g} /$ d. The total tumor GRF content based on its weight and IRGRF concentration (7) was $880 \mu \mathrm{g}$, indicating a turnover rate of $2.4 \%$. The absence of information concerning the turnover rate of GRF in the human hypothalamus precludes a reliable estimate of hypothalamic GRF secretion. However, the marked difference in GRF content between the tumor and the human hypothalamus, where preliminary results indicate levels to be in the submicrogram range (7), implies a considerably lower hypothalamic secretion rate.

Finally, the information provided by the disappearance rate study may provide a partial explanation for the more prolonged GH responses, particularly at 2 and $3 \mathrm{~h}$ noted after injection of high doses (1-10 $\mu \mathrm{g} / \mathrm{kg}$ ) of GRF (11). Whereas the minimal hpGRF (1-40) concentration in peripheral plasma required for stimulating GH release is unknown, we have recently reported that a constant infusion of $1 \mathrm{ng} / \mathrm{kg}$ per min is sufficient to elicit the plasma GH response in normal subjects (31). In the present study, this dose resulted in a plasma IR-GRF level of $0.35 \mathrm{ng} /$ ml. Examination of the GRF disappearance curves (Fig. 1) indicates that plasma IR-GRF levels after injection of 3.3 or 10 $\mu \mathrm{g} / \mathrm{kg}$ doses remained above this level for at least $3 \mathrm{~h}$, and after the $1 \mu \mathrm{g} / \mathrm{kg}$ dose, for $2 \mathrm{~h}$, thereby providing a continuous stimulus for $\mathrm{GH}$ release.

In conclusion, we have described methodology for measuring plasma IR-GRF levels after exogenous administration and have determined the MCR and plasma disappearance rate of hpGRF(1-40) after both single injection and constant infusion. The results have been extrapolated to provide estimates of GRF secretion rates in patients with ectopic GRF production.

\section{Acknowledgments}

The authors gratefully acknowledge the technical assistance of Jeanne Hirth, Pattie Hellmann, and the nursing staffs of the General Clinical Research Centers at the University of Cincinnati and the University of Virginia.

These studies were supported in part by U. S. Public Health Service grants AM 30667, AM 18722, and RR 0068 (Dr. Frohman), HL 01184 (Dr. Uderman), AM 26741 (Dr. Rivier and Dr. Vale), and AM 32632, HD 13197, and RR 847 (Dr. Thorner).

\section{References}

1. Wass, J. A. H. 1982. Somatostatin and its physiology in man in health and disease. In Clinical Neuroendocrinology, G. M. Besser and L. Martin, editors. Academic Press, Inc., New York. 2:359-395.

2. Guillemin, R., P. Brazeau, P. Bohlen, F. Esch, and N. Ling. 1982. Growth hormone-releasing factor from a human pancreatic tumor that caused acromegaly. Science (Wash. DC). 218:585-587.

3. Rivier, J., J. Spiess, M. Thorner, and W. Vale. 1982. Characterization of a growth hormone-releasing factor from a human pancreatic islet tumour. Nature (Lond.). 300:276-278.

4. Spiess, J., J. Rivier, M. Thorner, and W. Vale. 1982. Sequence analysis of a growth hormone releasing factor from a human pancreatic islet tumor. Biochemistry. 21:6037-6040.

5. Esch, F. S., P. Bohlen, N. C. Ling, P. E. Brazeau, W. B. Wehrenberg, M. O. Thorner, M. J. Cronin, and R. Guillemin. 1982. Characterization of a 40 residue peptide from a human pancreatic tumor with growth hormone releasing activity. Biochem. Biophys. Res. Commun. 109:152158.

6. Block, B., P. Brazeau, N. Ling, P. Bohlen, F. Esch, W. B. Wehrenberg, R. Benoit, F. Bloom, and R. Guillemin. 1983. Immunohistochemical detection of growth hormone releasing factor in brain. Nature (Lond.). 301:607-608

7. Frohman, L. A., J. L. Thominet, and M. Szabo. 1983. Comparison of immunologic and biologic activity of growth hormone-releasing factors (GHRF) from tumors associated with the ectopic GHRF syndrome. The Endocrine Society Annual Meeting, Abstract 14.

8. Spiess, J., J. Rivier, and W. Vale. 1983. Characterization of rat hypothalamic growth hormone-releasing factor. Nature (Lond.). 303:532535.

9. Thorner, M. O., R. L. Perryman, M. J. Cronin, A. D. Rogol, M. Draznin, A. Johnson, W. Vale, E. Horvath, and K. Kovacs. 1982. Somatotroph hyperplasia. Successful treatment of acromegaly by removal of a pancreatic islet tumor secreting a growth hormone-releasing factor. J. Clin. Invest. 70:965-977.

10. Thorner, M. O., J. Rivier, J. Spiess, J. L. Borges, M. L. Vance, S. R. Bloom, A. D. Rogol, M. J. Cronin, D. L. Kaiser, W. S. Evans, J. D. Webster, R. M. Macleod, and W. Vale. 1983. Human pancreatic growth-hormone-releasing factor selectively stimulates growth-hormone secretion in man. Lancet. I:24-28.

11. Vance, M. L., J. L. C. Borges, D. L. Kaiser, W. S. Evans, R. Furlanetto, J. L. Thominet, L. A. Frohman, A. D. Rogol, R. M. MacLeod, 
S. Bloom, J. Rivier, W. Vale, and M. O. Thorner. 1984. Human pancreatic tumor growth hormone releasing factor (hpGRF-40): dose response relationships in normal man. J. Clin. Endocrinol. Metab. In press.

12. MacGillivray, M., L. A. Frohman, and J. Doe. 1970. Metabolic clearance and production rates of human growth hormone in subjects with normal and abnormal growth. J. Clin. Endocrinol. Metab. 50:846852.

13. Leppauluoto, J., P. Virkkunen, and H. Lybeck. 1972. Elimination of TRH in man. J. Clin. Endocrinol. Metab. 35:477-478.

14. Redding, T., A. Kastin, D. Gonzalez-Barcena, D. H. Coy, E. J. Coy, D. S. Schalch, and A. V. Schally. 1973. The half-life, metabolism and excretion of tritiated luteinizing hormone-releasing hormone (LHRH) in man. J. Clin. Endocrinol. Metab. 37:626-631.

15. Sheppard, M., B. Shapiro, B. Pimstone, S. Kronheim, M. Berelowitz, and M. Gregory. 1979. Metabolic clearance and plasma half disappearance time of exogenous somatostatin in man. J. Clin. Endocrinol. Metab. 48:50-53.

16. Greenwood, F. C., W. M. Hunter, and J. S. Glover. 1963. The preparation of ${ }^{131}$ I-labelled human growth hormone of high specific radioactivity. Biochem. J. 89:114-123.

17. Rick, J., M. Szabo, P. Payne, N. Kovathana, J. G. Cannon, and L. A. Frohman. 1979. Prolactin-suppressive effects of two aminotetralin analogs of dopamine: Their use in the characterization of the pituitary dopamine receptor. Endocrinology. 102:1234-1242.

18. Frohman, L. A., M. Szabo, M. Berelowitz, and M. E. Stachura. 1980. Partial purification and characterization of a peptide with growth hormone-releasing activity from extrapituitary tumors in patients with acromegaly. J. Clin. Invest. 65:43-54.

19. Frohman, L. A., and L. L. Bernardis. 1968. Growth hormone and insulin levels in weanling rats with ventromedial hypothalamic lesions. Endocrinology. 82:1125-1132.

20. Berman, M., and M. F. Weis. 1977. SAAM Manual-Listing and Users' Information for SAAM 27. U. S. Dept. Health, Education, and Welfare, Public Health Service. National Institutes of Health, Bethesda, MD.

21. Tait, J., B. Little, S. Tait, and C. Flood. 1962. The metabolic clearance rate of aldosterone in pregnant and non-pregnant subjects estimated by both single-injection and constant-infusion methods. $J$. Clin. Invest. 41:2093-2100.

22. Tait, J. F. 1963. The use of isotopic steroids for the measurement of production rates in vivo. J. Clin. Endocrinol. Metab. 23:1285-1297.

23. Kohler, P. O., G. T. Ross, and W. D. Odell. 1968. Metabolic clearance and production rates of human luteinizing hormone in preand postmenopausal women. J. Clin. Invest. 47:38-47.

24. Sherwin, R. E., K. J. Kramer, J. D. Tobin, P. A. Insel, J. E. Liljenquist, M. Berman, and R. Andres. 1974. A model of the kinetics of insulin in man. J. Clin. Invest. 53:1481-1492.

25. Genuth, S. D. 1972. Metabolic clearance of insulin in man. Diabetes. 21:1003-1012.

26. Berelowitz, M., D. LeRoith, H. Von Schenk, C. Newgard, M. Szabo, L. A. Frohman, J. Shiloach, and J. Roth. 1982. Somatostatinlike immunoactivity and biologic activity is present in tetrahymena pyriformis, a ciliated protozoan. Endocrinology. 110:1939-1944.

27. Vasquez, B., V. Harris, and R. H. Unger. 1982. Extraction of somatostatin from human plasma on octadecylsilyl silica. J. Clin. Endocrinol. Metab. 55:807-809.

28. Nicholson, W. E., G. S. DeCherney, R. V. Jackson, C. R. DeBold, H. Uderman, A. N. Alexander, J. Rivier, W. Vale, and D. N. Orth. 1983. Plasma distribution, disappearance half-time metabolic clearance rate, and degradation of synthetic ovine corticotropin-releasing factor in man. J. Clin. Endocrinol. Metab. 57:1263-1269.

29. Matsuyama, H., A. Ruhmann-Wennhold, L. R. Johnson, and D. H. Nelson. 1972. Disappearance rates of exogenous and endogenous ACTH from rat plasma measured by bioassay and radioimmunoassay. Metab. Clin. Exp. 21:30-35.

30. Zafar, M. S., R. C. Mellinger, G. Fine, M. Szabo, and L. A. Frohman. 1979. Acromegaly associated with a bronchial carcinoid tumor. Evidence for ectopic production of growth hormone-releasing activity. J. Clin. Endocrinol. Metab. 48:66-71.

31. Webb, C. B., G. Perisutti, M. L. Vance, J. L. C. Borges, W. S. Evans, M. O. Thorner, and L. A. Frohman. 1983. Human growth hormone $(\mathrm{GH})$ releasing factor (GRF)-stimulated $\mathrm{GH}$ secretion. Decreased GH responsiveness after continuous infusion. Clin. Res. 31:763A. 